\title{
Assessment of tennis elbow using the Marcy Wedge-Pro
}

\author{
R. W. Smith MRCP, R. Mani PhD*, M. I. D. Cawley FRCP, W. Englisch DVMt and \\ P. Eckenberger MDt \\ Department of Rheumatology and *Department of Medical Physics, University of Southampton Hospitals, \\ Southampton, UK, and +Luitpold Pharma GmbH, Munich, Germany
}

\begin{abstract}
The Marcy Wedge-Pro (MWP), a device used in training by tennis players, was employed in the assessment of tennis elbow. The MWP was used to measure the ability of patients to perform wrist extension exercises, since pain resulting from this specific activity is a prominent symptom of the condition. The MWP results were compared with clinical measures and found to identify accurately patients who responded to treatment $(P<0.05)$. This study illustrates the potential of the MWP to assess tennis elbow quantitatively.
\end{abstract}

Keywords: Tennis elbow, pain, visual analogue scale (VAS), Marcy Wedge-Pro (MWP)

Tennis elbow is a common, often chronic condition with a prevalence of $1-3 \%$ in the general population $^{1,2}$. Tennis players are especially prone to this disorder with a cumulative incidence of up to $40 \%{ }^{3}$. Tennis elbow is considered to be a strain injury of the enthesis due to repetitive mechanical stresses acting at the origin of the common forearm extensor muscle group, specifically extensor carpi radialis brevis ${ }^{4}$. Diagnostic features of tennis elbow include a history of localized lateral humeral epicondylar pain and tenderness, with exacerbation of pain on contraction or passive stretching of the extensor muscle group 5 .

Despite the different treatments available for tennis elbow, there is no consensus on optimal management $t^{6,7}$. One reason for this may be that there is no specific, objective method of assessment ${ }^{7}$. Thus, there is a need for accurate and quantitative measures which are relevant to the main symptom, which is epicondylar pain on muscle activity.

Pain scoring systems including visual analogue scales (VAS) have been used, but these depend on patient perception ${ }^{8,9}$. Grip strength using a sphygmomanometer cuff is an objective measure which has been used widely ${ }^{10-14}$. However this exercise lacks specificity, since the forearm extensors act as muscles of synergy at the wrist, and grip strength is derived from finger flexion.

Address for correspondence: $\mathrm{Dr}$ R. W. Smith, Department of Rheumatology, University of Southampton Hospitals, Tremona Road, Shirley, Southampton, SO9 4XY, UK

(C) 1993 Butterworth-Heinemann Ltd 0306-3674/93/040233-04
Following on from previous work in painful frozen shoulder in which local autonomic dysfunction was identified, the aim of this study was to examine for similar changes in other forms of soft tissue rheumatism ${ }^{15,16}$. Our intention was to investigate the effects of clinical improvement in tennis elbow, and not to compare the efficacy of different treatments. The work presented here concerns the methods used to monitor clinical response. For this purpose we evaluated a device used in training by tennis players, called the Marcy Wedge-Pro (MWP; Escalade International, Swansea, UK) shown in Figure 1. The MWP provided objective and quantitative measures of the ability to exercise the forearm extensor muscle group.

\section{Patients and methods}

Ten consecutive patients referred with unilateral tennis elbow were studied. The inclusion criteria were: a typical history of local pain and epicondylar tenderness; an increase in pain on resisted wrist extension; and the absence of other elbow disease. Local Ethical Committee approval was obtained and all patients gave prior informed written consent. There were wide variations in severity and duration of symptoms, precipitating factors, and prior treatments as shown in Table 1.

Patients were assessed on four occasions, twice for baseline measures, and following treatment, 1 and 4 weeks later. Therapy was given as deemed appropriate (by the author RWS) (Table 1), together with advice to rest for 1 week. Clinical measures were VAS to assess pain on digital enthesis pressure and exercise, and a self-reported questionnaire for forearm disability in the previous week.

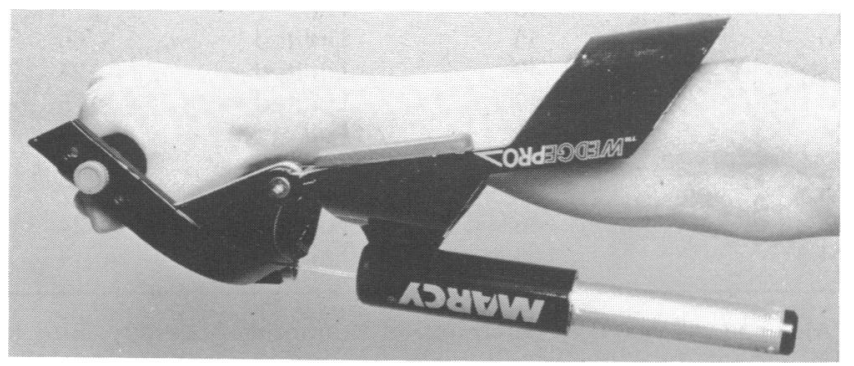

Figure 1. The Marcy Wedge-Pro (MWP) 


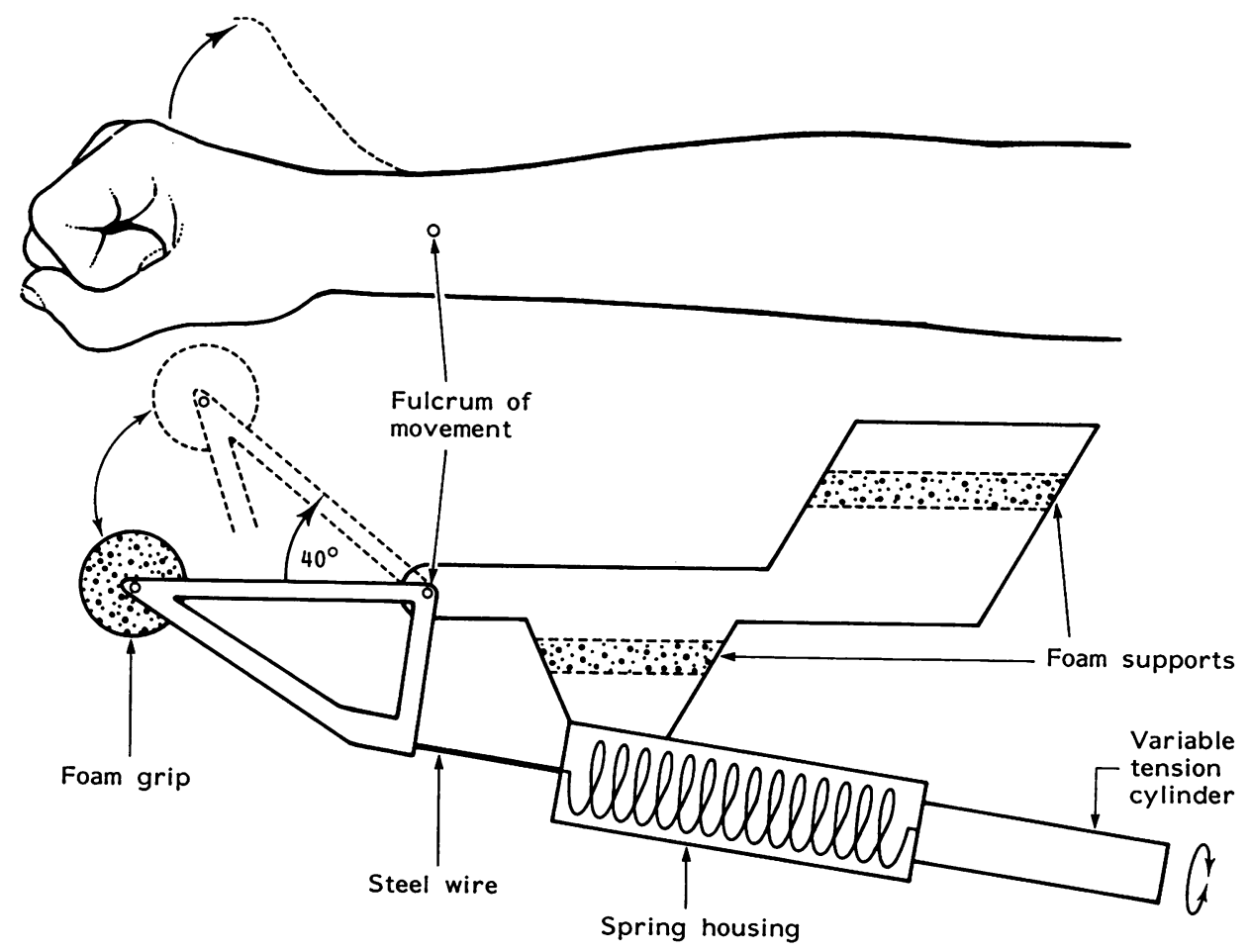

Figure 2. The MWP was used to test repetitive wrist extension exercises using a protocol which required $40^{\circ}$ of extension

The MWP was used to measure the ability to perform wrist extension exercises using both unaffected and affected arms in this order at each visit. Patients were seated, elbows flexed to $90^{\circ}$ resting on a couch with forearms in the mid-supine/prone position and placed in the MWP as illustrated in Figure 1. The spring of the MWP was adjusted to a pre-set tension throughout the study. With the wrist in the anatomical position $\left(0^{\circ}\right)$ tension was $1.950 \mathrm{~kg}$ (Figure 2). Patients were required to extend the wrist by an angle of $40^{\circ}$ and return to the anatomical position to complete each exercise cycle. This was measured on a scale on the MWP. A target of 50 cycles was set and patients were requested to perform this exercise repeatedly, but to stop in the event of pain. The MWP performances in individual patients following treatment were compared with baseline data.

Student's $t$ test was used to compare paired parametric data and McNemar's test for nonparametric disability ratings. Finally, patients were classified by their clinical response. Responders were defined by the absence of disability and an improvement in both VAS scores. A two-tailed Fisher's test of exact probability was used to compare this classification with the outcomes as expressed by MWP data.

\section{Results}

Table 1 includes details of outcome in individual patients following therapy. Table 2 summarizes

Table 1. Details of tennis elbow patients, therapy and outcome

\begin{tabular}{|c|c|c|c|c|c|c|c|}
\hline Sex & $\begin{array}{c}\text { Age } \\
\text { (years)* }\end{array}$ & $\begin{array}{l}\text { Activity } \\
\text { (visit 1) }\end{array}$ & $\begin{array}{c}\text { Duration } \\
\text { (months)t }\end{array}$ & $\begin{array}{l}\text { Precipitating } \\
\text { events }\end{array}$ & $\begin{array}{l}\text { Therapy } \\
\text { given } \neq\end{array}$ & $\begin{array}{l}\% \text { Change } \\
\text { MWP score }\end{array}$ & $\begin{array}{c}\text { Clinical } \\
\text { improvement }\end{array}$ \\
\hline$M$ & 42 & Nil & 20 & DIY & HA inj & +163 & Yes \\
\hline$M$ & 38 & Full & 1 & Squash & NSAID & +13 & Yes \\
\hline$M$ & 56 & Limited & 60 & Unknown & $\mathrm{T}$ inj & +74 & Yes \\
\hline $\mathbf{F}$ & 49 & Limited & 24 & Shopping & T inj & -11 & No \\
\hline$M$ & 45 & Limited & 5 & DIY & T inj & +316 & Yes \\
\hline $\mathbf{F}$ & 36 & Limited & 36 & Housework & $T$ inj & -8 & No \\
\hline$M$ & 31 & Limited & 17 & Lifting & $T$ inj & +400 & Yes \\
\hline$M$ & 46 & Full & 24 & DIY & NSÁID & -20 & No \\
\hline$M$ & 63 & Full & 4 & Gardening & HA inj & +47 & Yes \\
\hline
\end{tabular}

*Mean age 45 years; tmean duration 21 months; ¥Therapy: $\mathrm{T}$ inj, local injection 10-20 $\mathrm{mg}$ triamcinolone hexacetonide $+1 \mathrm{ml}$ lignocaine $1 \%$; HA inj, local injection $25 \mathrm{mg}$ hydrocortisone acetate $+1 \mathrm{ml}$ lignocaine 1\%; NSAID, non-steroidal anti-inflammatory drug, Topical Felbinac Gel 3\%, four times daily for 1 week 
Table 2. Reported forearm activity in previous week*

\begin{tabular}{lcccc}
\hline & Visit 1 & Visit 2 & Visit 3 & Visit 4 \\
\hline Nil & 1 & 1 & 5 & 0 \\
Limited & 5 & 7 & 4 & 2 \\
Full & 4 & 2 & 1 & 8 \\
\hline
\end{tabular}

*Values are patient numbers; $P<0.05$

changes in disability and shows that eight patients reported full activity at the final visit $(P<0.05)$. Mean parametric measures improved, shown graphically in Figure 3 with levels of significance indicated. The MWP exercise performances increased for the affected arms, while pain on both VAS reduced. Seven patients improved clinically. There was no significant change in MWP data from the unaffected arms $(P>0.05)$
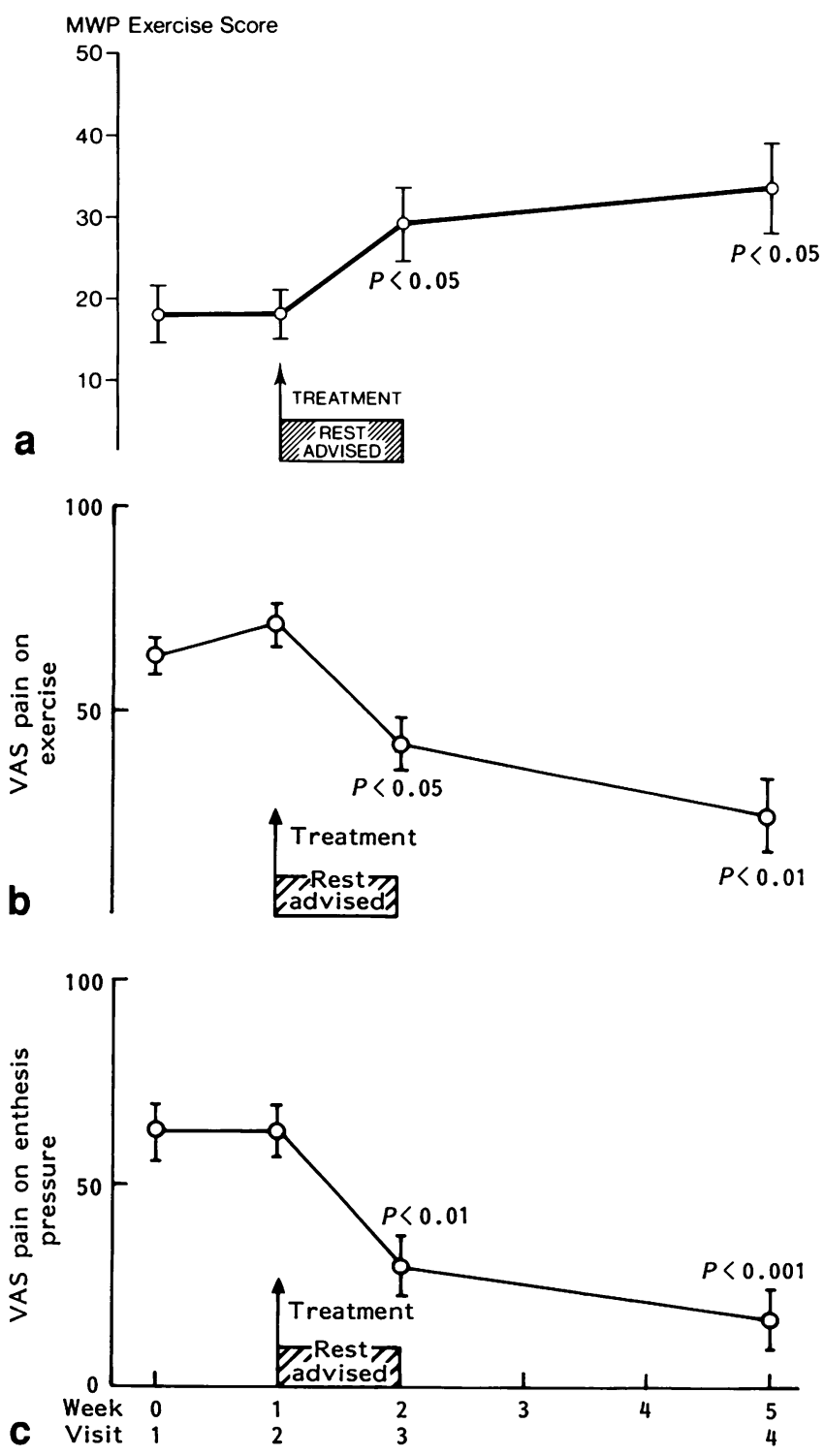

Figure 3. a MWP and b,c VAS data (mean \pm 1 s.e.) of affected arm
The MWP performances of the affected arms showed seven patients with improved performance (mean increase $=+150 \%$ ) and three in whom there was no change or a deterioration (mean $=-13 \%$ ). These results identified the same seven responders as the clinical classification $(P<0.05)($ Table 1$)$.

\section{Discussion}

In this study the MWP was used to quantify and monitor disability in tennis elbow. The MWP results were in agreement with other clinical measures of response. It provided objective and quantitative measures, which were sensitive and most importantly, relevant to the biomechanics of the condition. The exercise protocol used was reproducible and has the potential for modification. The MWP workload may be altered by adjusting the spring tension or angle of movement.

The diagnosis of tennis elbow is based on characteristic clinical features but there is a need for accurate measures of response to treatment, since therapy remains largely empirical. The ideal measure must take into account the dominant symptom, which is enthesis pain on exercise and in this regard the MWP is specific. These preliminary results suggest that the MWP is useful in the assessment of tennis elbow and we would recommend its use to others working in this field.

\section{Acknowledgements}

We would like to acknowledge the statistical advice of Dr M. J. Campbell of the University of Southampton Medical School.

\section{References}

1 Allander E. Prevalance, incidence and remission rates of some common rheumatic diseases and syndromes. Scand J Rheumatol 1974; 3: 145-53.

2 Binder AI, Hazleman BL. Lateral humeral epicondylitis - a study of natural history and the effect of conservative therapy. Br J Rheumatol 1983; 22: 73-6.

3 Gruchow HW, Pelletier D. An epidemiologic study of tennis elbow. Am J Sports Med 1979; 7: 234-8.

4 Wadsworth TG. Tennis elbow: conservative, surgical and manipulative treatment. $\mathrm{Br}$ Med J 1987; 294: 621-4.

5 Huskisson EC. The arthroses and diseases and injuries of the soft tissues. In: Wadsworth TG, ed. The Elbow. Edinburgh, UK: Churchill Livingstone, 1982: 283-302

6 Chard MD, Hazleman BL. Tennis elbow - a reappraisal. $\mathrm{Br} J$ Rheumatol 1989; 28: 186-9.

7 Burton AK. A comparative trial of forearm strap and topical anti-inflammatory as adjuncts to manipulative therapy in tennis elbow. Manual Medicine 1988; 3: 141-3.

8 Scott J, Huskisson EC. Graphic representation of pain. Pain 1976; 2: 175-84.

9 Kremer E, Hampton Atkinson Jr J. Pain measurement: construct validity of the affective dimension of the McGill pain questionnaire with chronic benign pain patients. Pain 1981; 11: 93-100.

10 Binder A, Parr G, Page Thomas P, Hazleman B. A clinical and thermographic study of lateral epicondylitis. Br J Rheumatol 1983; 22: 77-81.

11 Burton AK. Grip strength as an objective clinical assessment in tennis elbow. British Osteopathic Journal 1984; 16: 6-10.

12 Thurtle OA, Tyler AK, Cawley MID. Grip strength as a measure of response to treatment for lateral epicondylitis. $\mathrm{Br}$ Rheumatol 1984; 23: 154-5. 
13 Binder A, Hodge G, Greenwood AM, Hazleman BL, Page Thomas DP. Is therapeutic ultrasound effective in treating soft tissue lesions? Br Med J 1985; 290: 512-4.

14 Price R, Sinclair H, Heinrich I, Gibson T. Local injection treatment of tennis elbow - hydrocortisone, triamcinolone and lignocaine compared. $\mathrm{Br} J$ Rheumatol 1991; 30: 39-44.

15 Mani R, Cooper C, Kidd BL, Cole JD, Cawley MID. Use of laser Doppler flowmetry and transcutaneous oxygen electrodes to assess local autonomic dysfunction in patients with frozen shoulder. J Roy Soc Med 1989; 82: 536-8.

16 Smith RW, Mani R, Cawley MID. Use of laser Doppler flowmetry and transcutaneous oxygen electrodes to assess local autonomic dysfunction in epicondylitis. $\mathrm{Br} J$ Rheumatol 1992; 31 (Suppl 1): 22.

\section{AN UPDATE ON SPORTS MEDICINE}

\section{Conference and Medical Exhibition}

\section{Thursday 10th February, 1994}

\section{Crystal Palace National Sports Centre, London}

This one-day meeting is aimed at General Practitioners, Practice Nurses and Physiotherapists, and will be chaired by Dr Chris Jarvis, Medical Officer to the British Cycling Federation and Mrs Rose Macdonald, Director of the Sports Injury Centre, Crystal Palace.

The programme includes the following topics, together with an extensive Medical Exhibition:

- Diet for exercise - fact or fallacy

Gill Horgan, Accredited Sports Dietitian at the Sports Nutrition Foundation

- $\quad$ The injured knee - as presented in the surgery

Dr Paul Marfleet, Physician to the British Ultimate Federation

Mr Merlyn Fuller, Physiotherapist to the Colchester Rugby Club

- Doping - the clinician's dilemma

Professor Ian Macdonald

Dr D. Cowan, Director, Drug Control Centre, London

- $\quad$ Abdominal muscle training relating to back pain Mr Chris Norris, Physiotherapist to the Manchester Giants Basketball Club

How not to treat sports injuries

Dr P. Milroy, Medical Officer to the British Athletic Federation Amanda Johnson, Physiotherapist to the England Ladies Soccer Squad

- To jab or not to jab

Dr Malcolm Read, Consultant Orthopaedic and Sports Physician

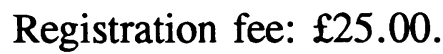

For further information please contact: Mr Malcolm Banks (Events Organiser), G.P. Forum, 10 Dobcroft Road, Sheffield S7 2LR. Tel/Fax: 0742351660. 